\title{
Therapy with high-dose long-term antioxidant free radicals for severe paraquat poisoning: A pilot study
}

\author{
SHUNLIN HU, CHUANHU QIAO, ZHENGLI YUAN, MIN LI, JIANGFENG YE, \\ HUIMIN MA, JINGHUI WANG, SIYI XIN and JING ZHANG
}

Department of Gastroenterology, Xiangyang First People's Hospital, Hubei University of Medicine, Xiangyang, Hubei 441000, P.R. China

Received March 16, 2018; Accepted September 6, 2018

DOI: $10.3892 / \mathrm{etm} .2018 .6823$

\begin{abstract}
This study investigated the effects of high-dose long-term antioxidant free radicals on the mortality rate, creatinine $(\mathrm{Cr})$ value, partial pressure of oxygen $\left(\mathrm{PaO}_{2}\right)$, alanine aminotransferase (ALT), as well as the incidence rates of lung fibrosis and dysfunction in the treatment of patients with severe paraquat (PQ) poisoning [toxic dose, $20 \mathrm{ml}$ stock solution $(20 \% \mathrm{w} / \mathrm{v})]$. A total of 23 cases of severe PQ poisoning treated in Xiangyang First People's Hospital, Hubei University of Medicine were collected (group 1), and they received conventional treatments such as immunosuppressive agents and/or hemoperfusion. Six patients were given high-dose long-term antioxidant therapy on the basis of conventional treatments (group 2). After treatment, 6 out of the 23 patients in group 1 survived, and all the 6 patients in group 2 survived, with the survival rate of 26.1 vs. $100 \%$ (p<0.01). The lowest $\mathrm{PaO}_{2}$ value in group 1 was lower than that in group $2(70.26 \pm$ 16.38 vs. $91.17 \pm 3.43 \mathrm{mmHg}, \mathrm{p}<0.01)$. The highest ALT value in group 1 was higher than that in group $2(216.74 \pm 126.23 \mathrm{vs}$. $52.50 \pm 24.83 \mathrm{U} / 1, \mathrm{p}<0.01)$. There was no significant difference in the incidence rate of lung fibrosis between the two groups of survived patients, but there were 6 patients that died of severe lung fibrosis in group 1. Besides, the incidence rate of lung dysfunction in patients in group 2 was significantly lower than that in survived patients in group $1(\mathrm{p}<0.01)$. High-dose long-term antioxidants are the most critical treatment option to improve the survival rate of high-dose PQ poisoning, they increase the patient's $\mathrm{PaO}_{2}$, enhance liver function, reduce lung fibrosis and refine lung dysfunction.
\end{abstract}

Correspondence to: Dr Jing Zhang, Department of Gastroenterology, Xiangyang First People's Hospital, Hubei University of Medicine, 15 Jiefang Avenue, Xiangyang, Hubei 441000, P.R. China E-mail: jt38gh@163.com

Key words: antioxidant free radicals, paraquat poisoning, lung fibrosis, reactive oxygen species

\section{Introduction}

Paraquat (PQ), as an electron acceptor, induces a large number of reactive oxygen species (ROS) upon entry into the mitochondria, thus resulting in damage to tissue cells $(1,2)$. After oral administration of PQ, PQ is quickly absorbed by the blood and actively transported into cells by inverse chemical gradients of type I and II lung cells, leading to a significant increase in the concentration in the lung, which is 6-10 times as high as that of the plasma concentration. Even though the plasma PQ concentration significantly declines, it can still be maintained at a high concentration within the lung, so the lung is its main target organ. In addition, PQ triggers the alveolar interstitial infiltration of a large number of inflammatory cells, which causes acute lung injury in the early stage and results in lung fibrosis in the advanced stage, so it is the main cause of death of patients. Liver and kidney damage in patients can jointly lead to multiple organ failure (3). PQ in the blood is mainly excreted through the kidney as a prototype. The direct toxic effects of PQ on the renal tubules can cause acute kidney function impairment and delayed excretion of PQ (4). Maintaining the kidney function is very important for reducing the PQ concentration in the plasma, which can also reduce the accumulation of PQ in lung cells (5).

The lethal dose of orally administered PQ is $\sim 20 \mathrm{ml}$, and the mortality rate is positively related to $P Q$ intake. The mortality rate of patients with high-dose poisoning reaches $60-90 \%$, and the survival rate of patients taking $>60 \mathrm{ml} P Q$ is $<1 \%$. Besides, survivors are also often companied by severe lung fibrosis, thus seriously affecting the respiratory function of patients (5).

The current treatment regimens for PQ are mainly early gastric lavage, oral administration of cathartic agents, oral administration of activated carbon and increased infusion quantity, excretion of PQ accelerated by diuretics, early hemoperfusion, and the applications of immunosuppressive agents and conventional antioxidants (5-7). However, according to the actual observation in Xiangyang First People's Hospital, Hubei University of Medicine (Xiangyang, China) and the literature reports, the mortality rate of patients with severe $\mathrm{PQ}$ poisoning is high $(5,6)$. At present, there is no recognized specific treatment for high-dose PQ poisoning, including the treatment with conventional antioxidants (5). 
The mass production of ROS is the main mechanism of PQ poisoning $(1,3,8)$, and a large number of cell and animal experiments have confirmed the effectiveness of antioxidative therapy (9), but only two clinical reports have suggested that antioxidant therapy is effective $(10,11)$. Observation in clinical practice and the literature analysis have indicated that conventional antioxidant therapy does not effectively improve the survival rate of patients. Therefore, there is currently no consensus on the application of antioxidants as the primary treatment method $(5,6)$.

For a long time, the core issue ignored in the clinical treatment for PQ poisoning is whether ROS can be effectively cleared, which is the key to determining the success of treatment in patients with high-dose $\mathrm{PQ}$ poisoning. Considering that PQ induces ROS generation in a dose-dependent manner (12), and that antioxidants inhibit ROS in a dose-dependent manner $(12,13)$, antioxidants at the conventional dose cannot effectively increase the survival rate. Therefore, it was proposed for the first time to employ high-dose long-term antioxidants for treating patients with severe PQ poisoning, so as to observe changes in the patient's survival rate, lung fibrosis and function.

\section{Materials and methods}

General data of patients. Group 1: a total of 23 hospitalized patients with PQ poisoning in the hospital from January 2011 to May 2013 were selected after patients with the oral dose of $<20 \mathrm{ml}$ were excluded.

Group 2: a total of 6 hospitalized patients in the hospital from June 2013 to March 2017 were selected after patients with the oral dose of $<20 \mathrm{ml}$ were excluded.

The study was approved by the Ethics Committee of Xiangyang First People's Hospital, Hubei University of Medicine. The patients who participated in this research, signed an informed consent and had complete clinical data.

Treatment regimens. Group 1: all patients underwent conventional hemoperfusion, followed by continuous venovenous hemofiltration (CVVH) and glucocorticoid treatment (methylprednisolone, 40-80 $\mathrm{mg} /$ day), and they received intravenously vitamin C ( $2 \mathrm{~g} /$ day) and orally took activated carbon, so as to maintain the electrolyte balance. Antibiotic therapy and other therapies were conducted when patients were complicated with infection, and they received ventilator-assisted respiration when respiratory failure occurred. Following the acute lung injury phase, patients were given $40 \mathrm{mg}$ prednisone daily with weekly reduction of $5 \mathrm{mg}$ after discharge, and the administration was kept for 1 month after the dose was reduced to $5 \mathrm{mg}$ daily, followed by discontinuation.

Group 2: after the approval was gained from patients and their family members, the dose of vitamin $\mathrm{C}$ was changed to $3 \mathrm{~g} \mathrm{q} .8 \mathrm{~h}$ (intravenous drip) on the basis of the conventional therapy, and that of glutathione (GSH) was changed to $2.4 \mathrm{~g} \mathrm{q} .12 \mathrm{~h}$ (intravenous drip). Seven days later, the dose of vitamin $\mathrm{C}$ was changed to $3 \mathrm{~g}$ q.12 h, and that of GSH was changed to 2.4 g q.d, with hospital stays of 10-14 days. After discharge, patients were orally administered with $0.6 \mathrm{~g}$ acetyl cysteine tablets twice a day for a total of 3 months. Besides, $40 \mathrm{mg}$ prednisone tablets were given to patients daily, with
Table I. Characteristics of the two groups of patients with PQ poisoning.

\begin{tabular}{lccc}
\hline Variables & $\begin{array}{c}\text { Group 1 } \\
(\mathrm{n}=23)\end{array}$ & $\begin{array}{c}\text { Group 2 } \\
(\mathrm{n}=6)\end{array}$ & P-value \\
\hline Age (years) & $33.70 \pm 10.50$ & $35.50 \pm 12.86$ & 0.723 \\
Male & $12(52.2 \%)$ & $2(33.3 \%)$ & 0.651 \\
Amount of ingested & & & \\
PQ (ml) & $42.17 \pm 14.13$ & $48.33 \pm 38.17$ & 0.713 \\
Time interval (h) & $5.26 \pm 2.14$ & $5.83 \pm 2.48$ & 0.576 \\
\hline
\end{tabular}

PQ, paraquat.

Table II. Various detection indicators of the two groups of patients before admission.

\begin{tabular}{lrrr}
\hline Variables & Group 1 $(\mathrm{n}=23)$ & Group 2 $(\mathrm{n}=6)$ & P-value \\
\hline $\mathrm{WBC}\left(10^{9} / \mathrm{l}\right)$ & $10.05 \pm 2.35$ & $9.55 \pm 2.60$ & 0.651 \\
$\mathrm{PaO}_{2}(\mathrm{mmHg})$ & $95.57 \pm 5.35$ & $96.33 \pm 6.25$ & 0.764 \\
$\mathrm{PaCO}_{2}(\mathrm{mmHg})$ & $39.09 \pm 3.09$ & $38.83 \pm 2.64$ & 0.856 \\
$\mathrm{ALT}(\mathrm{U} / \mathrm{l})$ & $37.04 \pm 4.43$ & $37.50 \pm 2.81$ & 0.813 \\
$\mathrm{Cr}(\mathrm{mg} / \mathrm{dl})$ & $1.10 \pm 0.20$ & $1.06 \pm 0.20$ & 0.608
\end{tabular}

WBC, white blood cell; $\mathrm{PaO}_{2}$, partial pressure of oxygen; $\mathrm{PaCO}_{2}$, partial pressure of carbon dioxide; ALT, alanine aminotransferase; $\mathrm{Cr}$, creatinine.

weekly reduction of $5 \mathrm{mg}$, and the administration was kept for 1 month after the dose was reduced to $5 \mathrm{mg}$ daily, followed by discontinuation.

Before treatment, oral PQ dose, time interval from administration to treatment, white blood cell (WBC), creatinine $(\mathrm{Cr})$, alanine aminotransferase (ALT), partial pressure of oxygen $\left(\mathrm{PaO}_{2}\right)$ and partial pressure of carbon dioxide $\left(\mathrm{PaCO}_{2}\right)$ of patients in each group were collected.

The survival rate evaluation after the end of treatment: patients were regarded as survived if they were alive for 6 months or longer from the date of hospitalization. The highest $\mathrm{Cr}$ and ALT values of patients were taken as indicators for liver and kidney damage. The lowest $\mathrm{PaO}_{2}$ value of patients was seen as the indicator for acute respiratory function impairment. Lung fibrosis was evaluated according to the chest X-ray examination results of patients. Moreover, the lung dysfunction of the survived patients was determined based on the existence of chest tightness and dyspnea after physical activities.

Statistical analysis. Statistical Product and Service Solutions (SPSS) 22.0 was applied for statistical analysis. Enumeration data are expressed as case (n) and percentage. As the total number of samples was $<40$, Fisher's exact test was used to analyze intergroup differences. Measurement data were presented as mean \pm standard deviation, and intergroup differences were analyzed via the independent samples t-test. $\mathrm{P}<0.05$ indicates that the difference is statistically significant. 


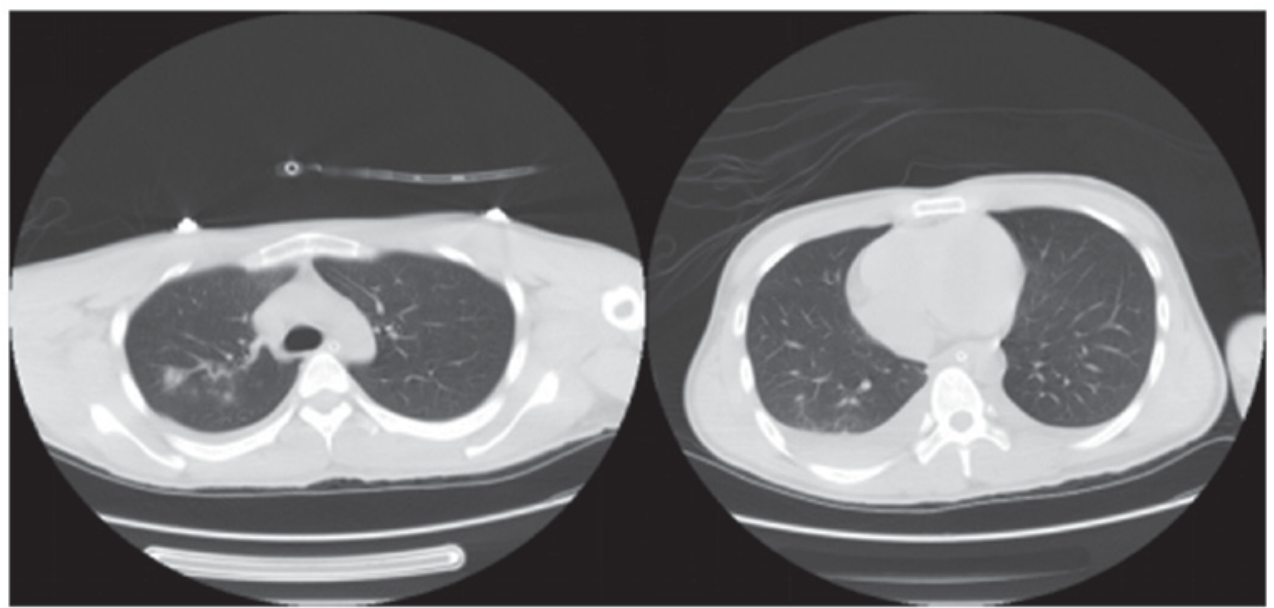

Figure 1. A 22-year-old male patient in group 1 took orally $80 \mathrm{ml} \mathrm{PQ}$. The lung CT signs on the 7th day after treatment are displayed, and the results manifested a double lung infection and pleural effusion formation. Due to the progressive appearance of severe hypoxemia and respiratory failure, ventilator-assisted respiration was performed, with the lowest $\mathrm{PaO}_{2}$ of $31 \mathrm{mmHg}$. The patient died of acute lung injury on the 10th day. PQ, paraquat; $\mathrm{CT}$, computed tomography; $\mathrm{PaO}_{2}$, partial pressure of oxygen.

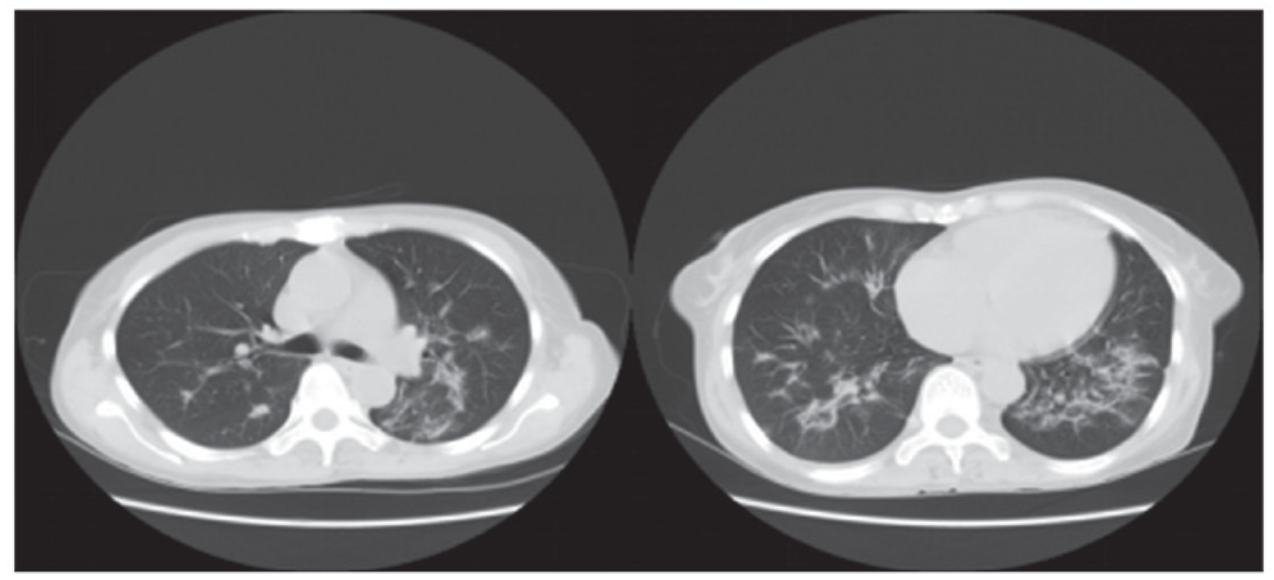

Figure 2. A 53-year-old female patient in group 2 took orally $120 \mathrm{ml} \mathrm{PQ}$. The lung CT signs on the 8th day after treatment are displayed, and the results revealed a large-area double lung infection, fibrosis and a small amount of pleural effusion. However, the patient never showed hypoxemia, with the lowest $\mathrm{PaO}_{2}$ of $90 \mathrm{mmHg}$, and she was discharged after the disease was controlled stable on the 14th day. A retrospective review of chest radiographs at $3 \mathrm{months}$ after discharge revealed the existence of only mild lung fibrosis, and the 2-year follow-up indicated that there was no dyspnea in the patient after physical activities. $\mathrm{PQ}$, paraquat; CT, computed tomography; $\mathrm{PaO}_{2}$, partial pressure of oxygen.

Table III. Analysis of the mortality rate of the two groups of patients.

\begin{tabular}{lccr}
\hline Groups & Death (n, \%) & Survival (n, \%) & P-value \\
\hline Group 1 & $17(73.9)$ & $6(26.1)$ & 0.002 \\
Group 2 & $0(0.0)$ & $6(100.0)$ & \\
\hline
\end{tabular}

\section{Results}

There was no significant difference in the basic data between the two groups of patients $(\mathrm{p}>0.05)$ (Table I).

The independent samples t-test was conducted for the two groups of patients before treatment, which revealed that there were no significant differences in $\mathrm{WBC}, \mathrm{PaO}_{2}, \mathrm{PaCO}_{2}, \mathrm{ALT}$ and $\mathrm{Cr}(\mathrm{p}>0.05)$, suggesting that there are no obvious differences
Table IV. Analysis of the difference in the incidence rate of lung fibrosis between the two groups of patients.

\begin{tabular}{llll}
\hline & \multicolumn{2}{c}{ Lung fibrosis $(\mathrm{n}, \%)$} & \\
\cline { 2 - 3 } Groups & \multicolumn{1}{c}{ No } & \multicolumn{1}{c}{ Yes } & P-value \\
\hline Group 1 & $0(0.0)$ & $6(100.0)$ & 0.182 \\
Group 2 & $3(50.0)$ & $3(50.0)$ & \\
\hline
\end{tabular}

in the infection index, lung, liver and kidney function between the two groups of patients before admission (Table II).

Fisher's exact test demonstrated that the survival rate of group 1 was lower than that of group 2, and the difference was statistically significant $(\mathrm{p}<0.05)$, indicating that the high-dose long-term antioxidant therapy significantly improves the patient's survival rate (Table III). 
Table V. Analyses of Cr value of the two groups of patients before and after treatment.

\begin{tabular}{lccr}
\hline Variables & $\begin{array}{c}\text { Cr value } \\
\text { before treatment } \\
(\mathrm{mg} / \mathrm{dl})\end{array}$ & $\begin{array}{c}\text { Cr value } \\
\text { after treatment } \\
(\mathrm{mg} / \mathrm{dl})\end{array}$ & P-value \\
\hline Group 1 & $1.10 \pm 0.20$ & $2.95 \pm 1.85$ & $<0.001$ \\
Group 2 & $1.06 \pm 0.20$ & $1.86 \pm 0.75$ & 0.061 \\
P-value & 0.608 & 0.173 & \\
\hline
\end{tabular}

$\mathrm{Cr}$, creatinine.

Table VI. Analyses of ALT of the two groups of patients before and after treatment.

\begin{tabular}{lccr}
\hline Variables & $\begin{array}{c}\text { ALT before } \\
\text { treatment (U/1) }\end{array}$ & $\begin{array}{c}\text { ALT after } \\
\text { treatment (U/l) }\end{array}$ & P-value \\
\hline Group 1 & $37.04 \pm 4.43$ & $216.74 \pm 126.23$ & $<0.001$ \\
Group 2 & $37.50 \pm 2.81$ & $52.50 \pm 24.83$ & 0.189 \\
P-value & 0.813 & $<0.001$ & \\
\hline
\end{tabular}

ALT, alanine aminotransferase.

According to Fisher's exact test, there was no significant difference in the incidence rate of lung fibrosis among the survivors in either group ( $p>0.05$ ). However, 6 patients in group 1 died of respiratory failure due to severe lung fibrosis while there was no patient with severe lung fibrosis in group 2, suggesting that high-dose long-term antioxidants effectively reduce lung fibrosis in patients (Table IV, Figs. 1 and 2).

The results manifested that after the independent samples t-test, there was no statistically significant difference in the highest $\mathrm{Cr}$ value between the two groups of patients before and after treatment $(\mathrm{p}>0.05)$. The paired sample $\mathrm{t}$-test illustrated that in group $1, \mathrm{Cr}$ value after treatment was higher than that before treatment, and the difference was statistically significant $(\mathrm{p}<0.05)$, suggesting that severe $\mathrm{PQ}$ poisoning remarkably impairs kidney function of patients, but not revealing that long-term high-dose antioxidant therapy can protect the patient's kidney function (Table V).

Based on the results, the independent samples t-test demonstrated that there was no significant difference in preoperative ALT between the two groups ( $p>0.05$ ). After treatment, ALT in group 1 was higher than that in group 2, with statistically significant difference $(p<0.05)$. The paired sample t-test manifested that in group 1, ALT after treatment was higher than that before treatment, showing a statistically significant difference $(\mathrm{p}<0.05)$, which suggested that severe PQ poisoning obviously damages liver function of patients, and the high-dose long-term antioxidant therapy can protect liver function of patients (Table VI).

On the basis of the results, the independent samples t-test showed that there was no statistically significant difference in $\mathrm{PaO}_{2}$ between the two groups before treatment $(\mathrm{p}>0.05)$. After treatment, $\mathrm{PaO}_{2}$ in group 1 was lower than that in group 2,
Table VII. Analyses of $\mathrm{PaO}_{2}$ of the two groups of patients during hospitalization before and after treatment.

\begin{tabular}{lccr}
\hline & $\mathrm{PaO}_{2}$ before & $\mathrm{PaO}_{2}$ after & \\
Variables & treatment $(\mathrm{mmHg})$ & treatment $(\mathrm{mmHg})$ & P-value \\
\hline Group 1 & $95.57 \pm 5.35$ & $70.26 \pm 16.38$ & $<0.001$ \\
Group 2 & $96.33 \pm 6.25$ & $91.17 \pm 3.43$ & 0.230 \\
P-value & 0.764 & $<0.001$ & \\
\hline
\end{tabular}

$\mathrm{PaO}_{2}$, partial pressure of oxygen.

Table VIII. Analysis of the difference in the incidence rate of lung dysfunction between the two groups of patients.

\begin{tabular}{lccc}
\hline Groups & $\begin{array}{c}\text { No incidence of } \\
\text { lung dysfunction } \\
(\mathrm{n}, \%)\end{array}$ & $\begin{array}{c}\text { Incidence of } \\
\text { lung dysfunction } \\
(\mathrm{n}, \%)\end{array}$ & P-value \\
\hline Group 1 & $1(16.7)$ & $5(83.3)$ & 0.015 \\
Group 2 & $6(100.0)$ & $0(0.0)$ & \\
\hline
\end{tabular}

with a statistically significant difference $(\mathrm{p}<0.05)$. The paired sample t-test illustrated that in group $1, \mathrm{PaO}_{2}$ after treatment was lower than that before treatment, and the difference was statistically significant $(\mathrm{p}<0.05)$, manifesting that severe PQ poisoning significantly impairs lung function of patients, and the high-dose long-term antioxidant therapy can protect lung function of patients in the acute phase (Table VII).

Fisher's exact test revealed that the incidence rate of lung dysfunction in group 1 was higher than that in group 2, and the difference was statistically significant $(\mathrm{p}<0.05)$, indicating that the high-dose long-term antioxidant therapy can prevent lung dysfunction in survivors (Table VIII).

\section{Discussion}

The mortality rate of patients with severe PQ poisoning is extremely high, and there is currently no specific treatment for it. Clinical treatments mainly include immunosuppressive agents and early hemoperfusion, and the lung transplantation in the later period can increase the survival rate of patients to a limited degree $(6,7)$.

Efficient clearance of ROS is the core of the treatment for high-dose PQ poisoning, but few clinical papers discuss how to effectively clear ROS. In this study, high-dose long-term antioxidants successfully saved the life of all patients in group 2, and effectively relieved the patient's lung fibrosis and dysfunction in the advanced stage, in which its maximum oral dose reached $120 \mathrm{ml}$.

\section{Main mechanism of $P Q$ poisoning}

$P Q$ induces ROS mass production through mitochondria. PQ produces only a small amount of ROS if not ingested by mitochondria, whereas ROS produced by PQ ingested by mitochondria is significantly increased (2). After PQ enters mitochondria, $\mathrm{PQ}^{2+}$ gains electrons [originated 
from nicotinamide adenine dinucleotide phosphate oxidase (NADPH)] from the complex I at the electron transport chain (ETC), and then $\mathrm{PQ}^{2+}$ is reduced to a monovalent $\mathrm{PQ}^{+}$, which transfers electrons to $\mathrm{O}_{2}$ to form ROS, and is oxidized to $\mathrm{PQ}^{2+}$, thus forming a redox cycle that produces large amounts of ROS [such as superoxide radicals $\left(\mathrm{O}_{2}^{-}\right)$, hydrogen peroxide $\left(\mathrm{H}_{2} \mathrm{O}_{2}\right)$, and hydroxyl radicals $\left.(-\mathrm{OH})\right](1)$. However, literature has also revealed that complex III is the site of $\mathrm{PQ}^{2+}$ producing mass ROS (2). Therefore, regardless of the site of production, $\mathrm{PQ}^{2+}$ largely plucks electrons from the ETC through the redox cycle and delivers it to oxygen to form ROS, which is the primary mechanism of PQ poisoning.

$P Q$ destroys mitochondrial deoxyribonucleic acid (mtDNA) and ETC, resulting in secondary ROS increase. ROS can destroy cell proteins, DNA, cell membranes and other macromolecular substances, leading to cell death $(9,14)$. ETC in mitochondria is very sensitive to ROS and is easily damaged by ROS (15). PQ can lead to a significant reduction of mitochondrial respiratory chain complex in the lung, liver, kidney and brain tissues (15). A large number of basic studies have shown that the ETC injury, especially the complex I injury, will lead to a large number of electronic leaks to form ROS (16). PQ induces mtDNA and nuclear DNA (nDNA) oxidative damage (17). mtDNA encodes 13 of the 113 subunits of ETC, and oxidative damage to mtDNA leads to insufficient secondary synthesis of ETC (18). 8-Oxoguanine glycosylase 1 (OGG1) is a DNA repair enzyme that maintains the integrity of mtDNA and reduces ROS generation. However, OGG1 knockdown results in a significant increase in ROS, suggesting that mtDNA injury will further increase ROS generation (19).

ROS induces the production of inflammatory cytokines in large quantities. Another notable feature of PQ poisoning is the large increases of inflammatory cytokines and cells in the lung $(3,6)$. ROS is the most important signal molecule inducing inflammation. ROS induces nuclear factor of $\kappa$ light polypeptide gene enhancer in B cell inhibitor $\alpha(\mathrm{I} \kappa \mathrm{B}-\alpha)$ phosphorylation, so as to lead to dissociation of nuclear factor $\kappa$-light-chain-enhancer of activated B cell-I $\kappa \mathrm{B}-\alpha$ $(\mathrm{NF}-\kappa \mathrm{B}-\mathrm{I} \kappa \mathrm{B}-\alpha)$ complex. Then, $\mathrm{NF}-\kappa \mathrm{B}$ translocates into the nucleus and binds to $\kappa \mathrm{B}$ transcription factor, thus inducing the expression of various inflammatory cytokines [such as tumor necrosis factor- $\alpha$ (TNF- $\alpha$ ), interleukin-6 (IL-6), IL-8, and transforming growth factor- $\beta$ (TGF- $\beta$ )] $(3,20-22)$, and the inflammatory cytokine TNF can also promote the destruction of alveolar epithelial mitochondrial I, resulting in the production of ROS and the formation of a vicious circle (23). At the same time, ROS destroys the vascular epithelial cells and leads to the destruction of the intercellular junctions. Inflammatory cytokines induce inflammatory cells to enter the lung through the gap between the two vascular endothelia.

In summary, PQ induces a large number of inflammatory cytokines by inducing ROS generation, thus leading to apoptosis or necrosis of the lung epithelial cells in patients $(9,14)$, resulting in acute lung injury with multiple organ damage to such as the liver and kidney $(17,24)$, and triggering lung fibrosis in the later period, which is the main mechanism of PQ poisoning (3).

The role of antioxidants and confusion in clinical applications. Antioxidants directly combat ROS-induced cellular damage. A large number of cell and animal experiments have shown that antioxidants can reduce PQ-induced ROS generation, reduce cell death and protect the lung, liver and kidney function of patients $(11,17)$. The mortality rate of patients is mainly positively related to the patient's oral dose, and those who take $>60 \mathrm{ml}$ PQ almost never survive (5). The most important reason is that PQ induces ROS generation in a dose-dependent manner (12), and similarly, the effect of antioxidants is dose-dependent. High-dose antioxidants can effectively inhibit ROS generation (13).

Antioxidants restore the function of $m t D N A, E T C$ and mitochondria. Loss of mtDNA and damage to ETC are important sources of ROS generation (16). Mitochondrial GSH level is an important factor for maintaining the integrity of mtDNA. Antioxidants can reduce the formation of 8-hydroxy-2'-deoxyguanosine (8-OHdG), a DNA oxidative product, and restore the integrity of mtDNA (17). In addition, $N$-acetylcysteine (NAC) can restore the integrity of ETC with oxidative damage (25), thereby reducing ROS regeneration.

Antioxidants reduce the formation of inflammatory cytokines, inhibit the destruction of inflammatory cytokines to cells, and play an anti-lung fibrosis role. ROS, as an intracellular signaling molecule, induces the mass production of inflammatory cytokines, in which the mass production of TGF- $\beta$ is the main pathogenesis of lung fibrosis $(20,22)$. Inflammatory cytokines, such as TNF- $\alpha$, induce cell death primarily through the induction of intracellular ROS generation, whereas antioxidants reduce TNF- $\alpha$-induced cell death (26). Antioxidants can remarkably reduce the generation of various inflammatory cytokines, while reducing that of TGF- $\beta$ (20).

Therefore, in theory, antioxidative therapy is the core of the treatment for the disease, but the current antioxidative therapy is not regarded as the main treatment, and the patient's mortality rate is high $(5,6,27)$. There are few clinical reports on high-dose vitamin $\mathrm{C}$ treatment for PQ poisoning, but it can effectively protect kidney function and reduce the mortality rate $(10,11)$. Therefore, it is hypothesized that antioxidants at the conventional dosage cannot clear all ROS, which is the major cause of high mortality rate of patients.

Test results suggest that the high-dose long-term antioxidant therapy brings a good clinical effect. High-dose vitamin $\mathrm{C}$ (maximum dose of $3 \mathrm{~g}, 3$ times daily) and GSH (50 $\mathrm{mg} / \mathrm{kg}$, once daily) can effectively reduce the oxidant level in the body $(11,28)$ and increase the patient's survival rate $(10)$. Therefore, the aim of high-dose long-term antioxidant lies in effectively preventing the damaging effect of ROS on tissues, thereby increasing the patient's survival rate.

In the past, it was believed that the removal of large amounts of ROS was difficult to be achieved, so there is no report on the application of high-dose long-term antioxidants in the treatment of severe PQ poisoning (5).

The experimental results suggested that the high-dose long-term antioxidant therapy can effectively improve the patient's survival rate and reverse liver function impairment (24).

After patients get through the acute lung injury phase, another important issue is lung fibrosis $(3,20)$. Recent studies have shown that the increase of TGF- $\beta$ triggered by abnormal ROS in the lung is still the main factor for lung fibrosis $(20,21)$. 
mtDNA damage is an important molecular change of lung fibrosis (29). Early application of NAC can prevent the formation of lung fibrosis (30). Moreover, high-dose long-term antioxidant therapy can obviously reduce lung fibrosis in patients and improve lung function, suggesting that this therapy can effectively reduce the generation of the inflammatory cytokine TGF- $\beta$ in the lung, which is the most important factor for preventing lung fibrosis and enhancing lung function.

Conventional glucocorticoids resistant to lung fibrosis are considered as the main treatment option, but its actual effect is not good. High-dose glucocorticoids or cytotoxic drugs can also effectively improve the patient's survival rate and prevent lung fibrosis, but they cause serious side-effects such as increased infection, bone marrow suppression and osteoporosis that limit their clinical application (27).

In conclusion, the main pathogenesis of PQ poisoning is the induction of ROS and the mass production of inflammatory cytokines. Acute lung injury in patients and lung fibrosis in the later period are the main causes of death of patients. To the best of our knowledge, it is proposed in this study for the first time that the high-dose long-term antioxidant therapy is a specific treatment for serious PQ poisoning. The results evidenced that this therapy significantly improved the patient's survival rate, prevented lung fibrosis in the advanced stage, and improved lung and liver function of patients. It is hoped that more clinical studies will continue to validate the clinical efficacy of this therapy.

\section{Acknowledgements}

Not applicable.

\section{Funding}

No funding was received.

\section{Availability of data and materials}

The datasets used and/or analyzed during the present study are available from the corresponding author on reasonable request.

\section{Authors' contributions}

SH and CQ conceived and designed the experiments. $\mathrm{SH}$, JZ, ML and JY performed the experiments. JZ, HM and JW analyzed the data. SH, JZ, CQ, ZY, ML, JY, HM and JW contributed to providing reagents, materials and analysis tools. $\mathrm{SH}, \mathrm{ML}$ and SX wrote the manuscript. CQ and ZY revised and finalized the manuscript. ZY and SX were also involved in the conception and design of the study. All authors read and approved the final manuscript.

\section{Ethics approval and consent to participate}

The study was approved by the Ethics Committee of Xiangyang First People's Hospital, Hubei University of Medicine (Xiangyang, China). The patients who participated in this research, signed an informed consent and had complete clinical data.

\section{Patient consent for publication}

Not applicable.

\section{Competing interests}

The authors declare that they have no competing interests.

\section{References}

1. Cochemé HM and Murphy MP: Complex I is the major site of mitochondrial superoxide production by paraquat. J Biol Chem 283: 1786-1798, 2008.

2. Castello PR, Drechsel DA and Patel M: Mitochondria are a major source of paraquat-induced reactive oxygen species production in the brain. J Biol Chem 282: 14186-14193, 2007.

3. Dinis-Oliveira RJ, Duarte JA, Sánchez-Navarro A, Remião F, Bastos ML and Carvalho F: Paraquat poisonings: Mechanisms of lung toxicity, clinical features, and treatment. Crit Rev Toxicol 38: 13-71, 2008.

4. Weng $\mathrm{CH}$, Chen $\mathrm{HH}, \mathrm{Hu} \mathrm{CC}$, Huang WH, Hsu CW, Fu JF Lin WR, Wang IK and Yen TH: Predictors of acute kidney injury after paraquat intoxication. Oncotarget 8: 51345-51354, 2017.

5. Gil HW, Hong JR, Jang SH and Hong SY: Diagnostic and therapeutic approach for acute paraquat intoxication. J Korean Med Sci 29: 1441-1449, 2014

6. Gawarammana IB and Buckley NA: Medical management of paraquat ingestion. Br J Clin Pharmacol 72: 745-757, 2011.

7. Hsu CW, Lin JL, Lin-Tan DT, Chen KH, Yen TH, Wu MS and Lin SC: Early hemoperfusion may improve survival of severely paraquat-poisoned patients. PLoS One 7: e48397, 2012.

8. Bonilla E, Medina-Leendertz S, Villalobos V, Molero L and Bohórquez A: Paraquat-induced oxidative stress in drosophila melanogaster: Effects of melatonin, glutathione, serotonin, minocycline, lipoic acid and ascorbic acid. Neurochem Res 31: 1425-1432, 2006.

9. Cappelletti G, Maggioni MG and Maci R: Apoptosis in human lung epithelial cells: Triggering by paraquat and modulation by antioxidants. Cell Biol Int 22: 671-678, 1998.

10. Moon JM and Chun BJ: The efficacy of high doses of vitamin C in patients with paraquat poisoning. Hum Exp Toxicol 30: 844-850, 2011.

11. Hong SY, Hwang KY, Lee EY, Eun SW, Cho SR, Han CS, Park YH and Chang SK: Effect of vitamin C on plasma total antioxidant status in patients with paraquat intoxication. Toxicol Lett 126: 51-59, 2002.

12. Hong SY, Yang JO, Lee EY and Lee ZW: Effects of N-acetyl-L-cysteine and glutathione on antioxidant status of human serum and 3T3 fibroblasts. J Korean Med Sci 18: 649-654, 2003.

13. Hong SY, Gil HW, Yang JO, Lee EY, Kim HK, Kim SH, Chung YH, Hwang SK and Lee ZW: Pharmacokinetics of glutathione and its metabolites in normal subjects. J Korean Med Sci 20: 721-726, 2005.

14. Jang YJ, Won JH, Back MJ, Fu Z, Jang JM, Ha HC, Hong S, Chang $\mathrm{M}$ and Kim DK: Paraquat induces apoptosis through a mitochondria-dependent pathway in RAW264.7 cells. Biomol Ther (Seoul) 23: 407-413, 2015.

15. Musatov A and Robinson NC: Susceptibility of mitochondrial electron-transport complexes to oxidative damage. Focus on cytochrome $c$ oxidase. Free Radic Res 46: 1313-1326, 2012.

16. Indo HP, Davidson M, Yen HC, Suenaga S, Tomita K, Nishii T, Higuchi M, Koga Y, Ozawa T and Majima HJ: Evidence of ROS generation by mitochondria in cells with impaired electron transport chain and mitochondrial DNA damage. Mitochondrion 7: 106-118, 2007.

17. Ortiz MS, Forti KM, Suárez Martinez EB, Muñoz LG, Husain K and Muñiz WH: Effects of antioxidant $N$-acetylcysteine against paraquat-induced oxidative stress in vital tissues of mice. Int J Sci Basic Appl Res 26: 26-46, 2016.

18. Płoszaj T, Robaszkiewicz A and Witas H: Oxidative damage of mitochondrial DNA: The result or consequence of enhanced generation of reactive oxygen species. Postepy Biochem 56: 139-146, 2010 (In Polish).

19. Bacsi A, Chodaczek G, Hazra TK, Konkel D and Boldogh I: Increased ROS generation in subsets of OGG1 knockout fibroblast cells. Mech Ageing Dev 128: 637-649, 2007. 
20. Liu RM and Gaston Pravia KA: Oxidative stress and glutathione in TGF-beta-mediated fibrogenesis. Free Radic Biol Med 48: $1-15,2010$

21. Cheresh P, Kim SJ, Tulasiram S and Kamp DW: Oxidative stress and pulmonary fibrosis. Biochim Biophys Acta 1832: 1028-1040, 2013.

22. Mittal M, Siddiqui MR, Tran K, Reddy SP and Malik AB: Reactive oxygen species in inflammation and tissue injury. Antioxid Redox Signal 20: 1126-1167, 2014.

23. Mariappan N, Elks CM, Fink B and Francis J: TNF-induced mitochondrial damage: A link between mitochondrial complex I activity and left ventricular dysfunction. Free Radic Biol Med 46: 462-470, 2009

24. Awadalla EA: Efficacy of vitamin $C$ against liver and kidney damage induced by paraquat toxicity. Exp Toxicol Pathol 64: 431-434, 2012

25. Boer LA, Panatto JP, Fagundes DA, Bassani C, Jeremias IC, Daufenbach JF, Rezin GT, Constantino L, Dal-Pizzol F and Streck EL: Inhibition of mitochondrial respiratory chain in the brain of rats after hepatic failure induced by carbon tetrachloride is reversed by antioxidants. Brain Res Bull 80: 75-78, 2009.

26. Kamata H, Honda S, Maeda S, Chang L, Hirata H and Karin M: Reactive oxygen species promote TNFalpha-induced death and sustained JNK activation by inhibiting MAP kinase phosphatases. Cell 120: 649-661, 2005.
27. He F, Xu P, Zhang J, Zhang Q, Gu S, Liu Y and Wang J: Efficacy and safety of pulse immunosuppressive therapy with glucocorticoid and cyclophosphamide in patients with paraquat poisoning: A meta-analysis. Int Immunopharmacol 27: 1-7, 2015.

28. Kim JH, Gil HW, Yang JO, Lee EY and Hong SY: Effect of glutathione administration on serum levels of reactive oxygen metabolites in patients with paraquat intoxication: A pilot study. Korean J Intern Med (Korean Assoc Intern Med) 25: 282-287, 2010.

29. Kim SJ, Cheresh P, Jablonski RP, Williams DB and Kamp DW: The role of mitochondrial DNA in mediating alveolar epithelial cell apoptosis and pulmonary fibrosis. Int J Mol Sci 16: 21486-21519, 2015.

30. Yu WC, Tian LY and Cheng W: Efficacy study of edaravone and acetylcysteine towards bleomycin-induced rat pulmonary fibrosis. Int J Clin Exp Med 8: 8730-8739, 2015.

This work is licensed under a Creative Commons Attribution-NonCommercial-NoDerivatives 4.0 International (CC BY-NC-ND 4.0) License. 